\title{
Daylight Savings Calculation Technique for Smart Buildings
}

\author{
Dariusz Kacprzak ${ }^{1}$, Ioan Tuleasca ${ }^{2}$ \\ ${ }^{1}$ Department of Electrical and Computer Engineering, The University of Auckland, Auckland, New Zealand \\ ${ }^{2}$ The Open Polytechnic of New Zealand, Lower Hutt, New Zealand \\ Email: Ioan.Tuleasca@openpolytechnic.ac.nz
}

Received September 14, 2012; revised November 5, 2012; accepted November 12, 2012

\begin{abstract}
This publication presents a technique of quantifying energy savings due to daylight. The technique is designated to be used in smart buildings or similar applications where daylight harvesting is welcomed. The technique is divided into three stages. In the first stage an optical sensor is evaluated for its $\mathrm{P}$ (power)- $E$ (illumination) response characteristics. In the second stage the calibration of room properties is carried out. In the final stage photometric calculations are performed, and energy savings are calculated. The major advantage of the proposed approach is to determine energy savings during the design stage of a building, not after the building construction or retrofitting. The information obtained from the calculations is useful for investors, future tenants and environmentalists.
\end{abstract}

Keywords: Interior Lighting; ELS Sensor; Energy Savings; $\mathrm{CO}_{2}$ Emissions; ETAP Appliances

\section{Introduction}

It is common knowledge that lighting contributes to more than $30 \%$ of the total energy consumption of a building. Nowadays lighting systems in so-called smart buildings are optimised to ensure the minimum energy consumption. Such lighting systems are composed of energy efficient luminaires and daylight control, offering additional savings due to the natural light entering the building. In some applications occupancy control is also present. Comprehensive studies have been performed to ascertain how daylight harvesting can contribute to, and increase, energy savings in association with automated and manual control systems. Using numerical [1,2] (RELUX, MATLAB SIMULINK) and analytical methods [3-5], daylight utilization was analysed where dimming systems were generally ascertained to be the most suitable means for integrating the sustainable development concept. Calibrating the lighting system as well as continuing user and operator education were procedures deemed to be extremely important when using sophisticated control systems that include continuous daylight control and occupancy sensors [6]. A fuzzy logic based approach is described [7] and its implementation is analyzed in conjunction with DIALux ${ }^{\circledR}$. Since daylight is a dynamic, highly variable, season and location dependent, source of lighting, fuzzy logic may be a promising alternative to classical, mathematical modelling. In this paper the authors demonstrate a simple, straightforward and time effi- cient paradigm of including daylight harvesting calculations in electrical lighting designs. An example is provided where the Electrical and Computer Engineering ECE Department of the University of Auckland is chosen for performing measurements due to its accessibility, familiarity and, most important, due to the availability of software modelling files ".DWG". These files offer the layout of given locations and are appropriate for use with the lighting design software DIALux ${ }^{\circledR}$. State of the art appliances (ETAP luminaries and associated sensors/dimming ballasts from the Belgian company ETAP Electro Technische Apparaten) and measuring equipment (power meter, lux meter) are used for data gathering.

\section{Lighting Terminology, AS/NZS Standards, Appliances and Measuring Equipment}

The definitions of specific lighting quantities and their depiction for an appropriate understanding of the described assessment technique are subsequently presented.

Illuminance $\mathrm{E}$

Illuminance (Figure 1) is the amount of light coming from a light fixture that lands on a surface. It is measured in lux (lx).

Luminance $L$

Luminance describes the amount of light leaving a surface in a particular direction. Units: candela $/ \mathrm{m}^{2}$.

Maintenance Factor

The maintenance factor (light loss factor) is a value 


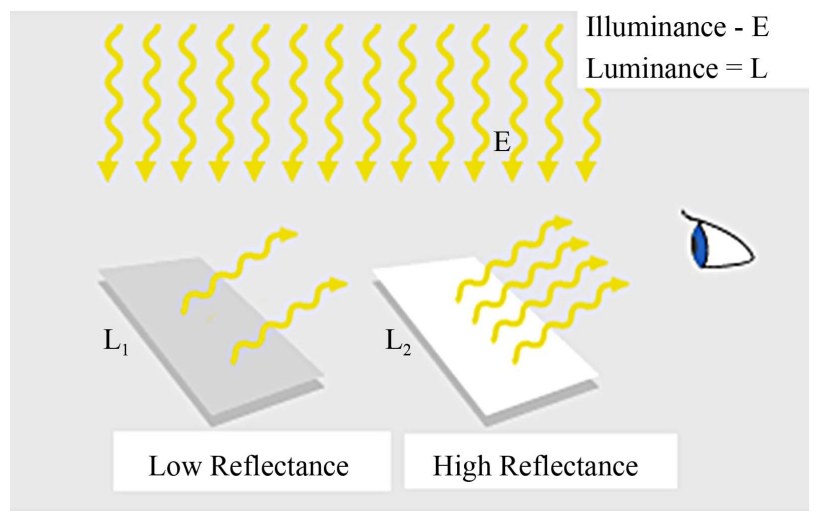

Figure 1. Lighting quantities.

designed to account for the reduction in light output from a lighting system due to ageing, dirt and dust on the light fittings.

\section{Reflection Coefficient}

The reflection coefficient (reflectance) is used to calculate the amount of light transmitted through a medium if the only losses considered are reflection losses.

\section{Uniformity Level}

The uniformity level is a dimensionless quantity that represents the ratio of $E_{\text {min }} / E_{\text {average }}$.

\section{Standards}

The prescriptions of the Australian/New Zealand Standard $^{\text {TM }}$ (AS/NZS 1680.0:2008) and of the New Zealand Green Building Council (NZGBC) were used for design purposes [8]. Table 1 presents the illuminance levels on the workplane according to the Interior and Workspace Lighting for Educational and Training Facilities section of the Standard.

\section{Luminaire $L$}

A luminaire is a complete light unit consisting of lamps, reflectors and other parts that hold the lamp in place and protect it. Choosing luminaires with the right type of lamp and reflector type, which efficiently provides the appropriate lighting patterns, is also an important part of energy efficient lighting design. Figure 2 shows a typical luminaire arrangement [9].

\section{Ballast}

Ballast is a device used to start a lamp by providing a shot of voltage and also control the current flow during its operation. There are 2 types of ballasts, magnetic and electronic. The electronic ones are preferred more because of their robustness and improved functionality and efficiency. The dimming ballast [10] reduces the amount of current entering the lamp in accordance with the daylight available and helps reduce power usage. A typical dimming ballast is depicted in Figure 3.

\section{Sensor}

The sensor, clipped onto the luminaire, regulates and shuts down the artificial light output in accordance with the level of natural light available [11]. The sensor used
Table 1. Lighting levels on the workplane.

\begin{tabular}{cc}
\hline Type of Interior or Activity & Maintained Illuminance [lx] \\
\hline $\begin{array}{c}\text { General tasks involving typing, } \\
\text { reading and writing }\end{array}$ & 320 \\
Computer rooms & 320 \\
Corridors & 80 \\
Stairs & 80 \\
Light level on the carpet/floor & 80
\end{tabular}

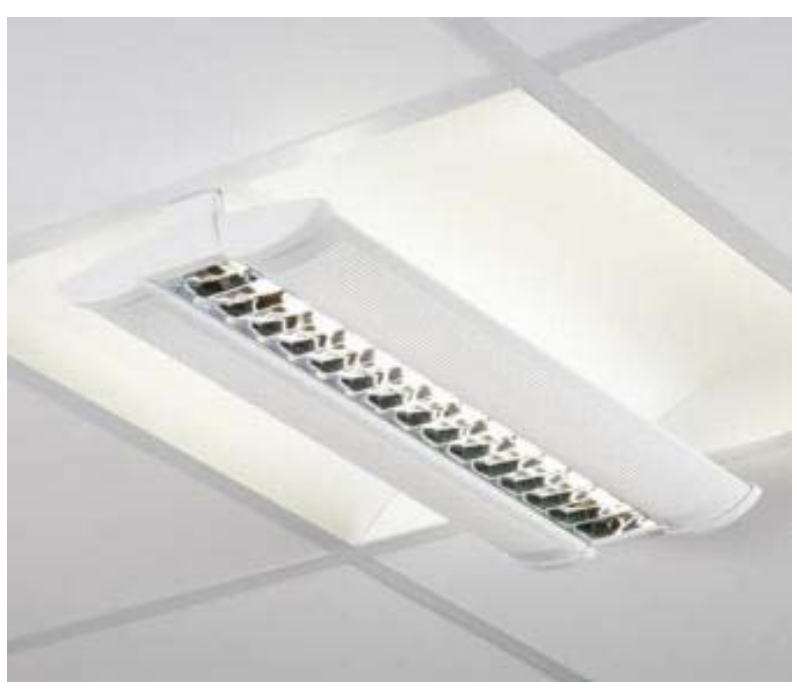

Figure 2. Luminaire.

for this project maintains a maximum illuminance level of approximately $500 \mathrm{~lx}$ at all times and operates at a voltage range of 1 - $10 \mathrm{~V}$. Figure 4 show a sensor on a luminaire (4a) and the layout of a complete unit (4b).

The sensor has a measuring field of $\varnothing 3$ meters at a height of 2.8 meters. It takes into account the luminance of the available daylight and of other artificial sources along with the reflection coefficient of the material present underneath. The dimming electronic ballast reduces the amount of current entering the lamp in accordance with the information received from the sensor.

Power Meter

A power meter provides the power reading of the luminaire. When used in connection with a sensor the power readings vary due to the amount of daylight available.

\section{Lux Meter}

A lux meter (Figure 5, next to a power meter) provides the illuminance reading in locations of choice.

\section{Power $P$ versus Illuminance $E$ Characteristic for an ELS Sensor Equipped ETAP Luminaire}

A novel technique is proposed where a sensor's power $\mathrm{P}$ versus illuminance $E$ curve is determined and subsequently used in inferring the power (energy consumption) 


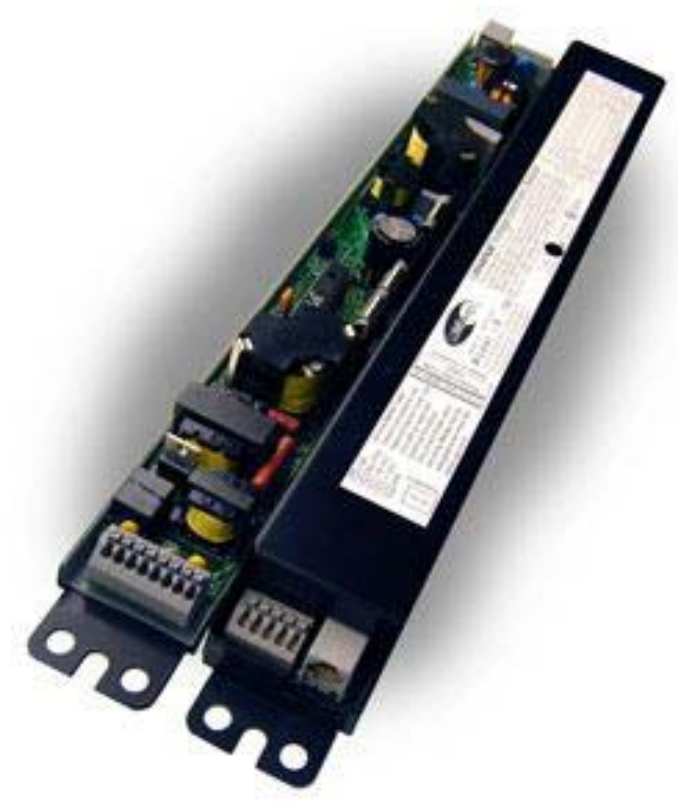

Figure 3. Ballast.

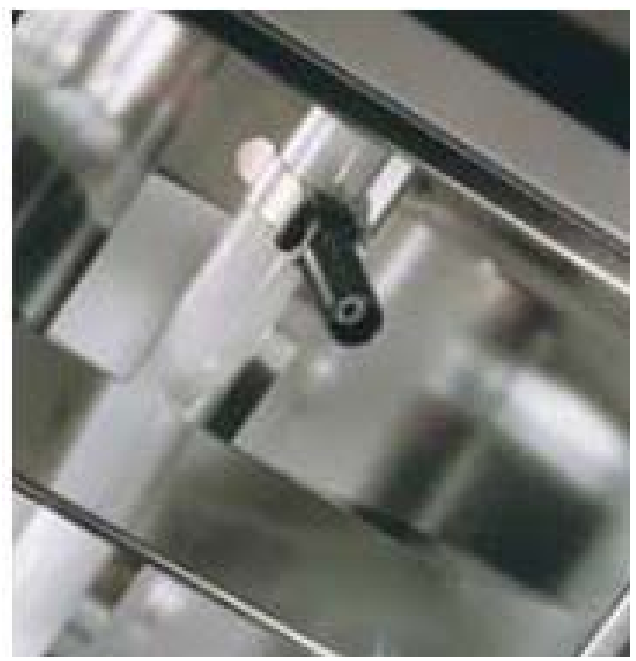

(a)

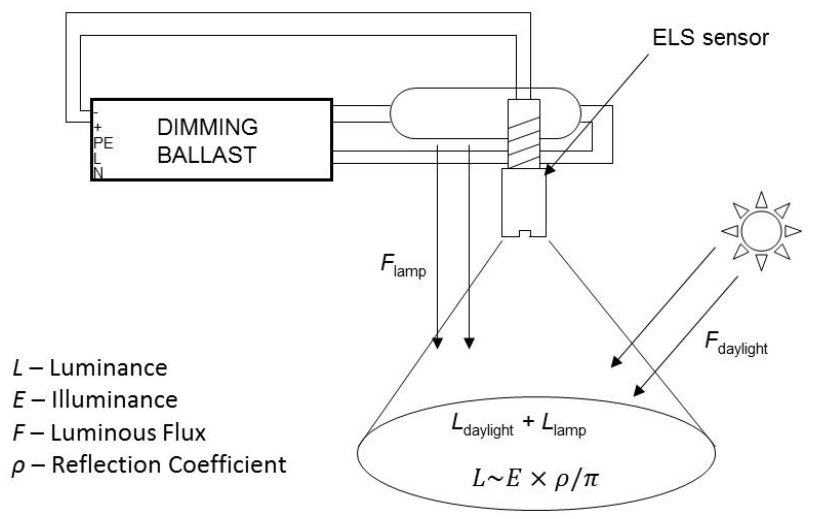

(b)

Figure 4. (a) Sensor attached to luminaire; (b) Graphical depiction of a complete unit.

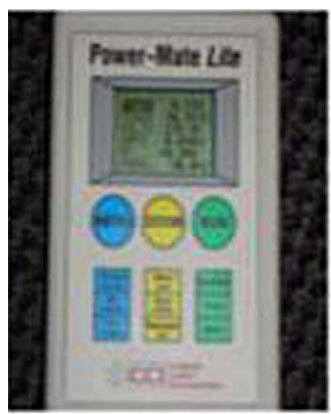

Power Meter

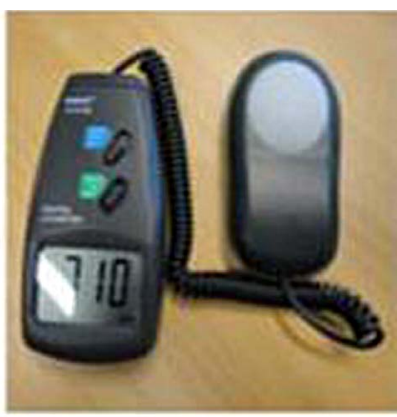

Lux Meter

Figure 5. Power meter and lux meter.

of the luminaire-sensor unit, for various levels of daylight affected illuminance $E$.

To illustrate the concept measurements were performed by placing an ELS (ETAP Lightig control System) sensor equipped ETAP luminaire (one lamp fixture) onto the ceiling at a height of $2.8 \mathrm{~m}$, as specified in Standards. Illuminance $E$, as seen by the ELS sensor, was varied, and the corresponding ETAP luminaire active power $\mathrm{P}$ measured (Figure 6). The measurements were performed using a lux meter that measured the illuminance $E$ at the ELS sensor's height, and a power meter, that measured the corresponding active power $\mathrm{P}$ of the ETAP luminaire. On the workplane the illuminance was maintained according to Standards.

The dependency P/E is the basis for accurately evaluating the energy consumed by a particular sensor/luminaire based lighting system designed using specialized lighting software (in this instance ELS sensor/ETAP luminaire unit and DIALux ${ }^{\circledR}$ software).

\section{DIALux ${ }^{\circledR}$ Features}

For the purpose of the present research an open lighting simulation software, DIALux ${ }^{\circledR}$, was selected and used. The software supports luminaire data for numerous global manufacturers in the form of "plugins" as well as ".DWG" file format that enables the user to reproduce/ use/transfer analyzed location's dimensions accurately. Some of DIALux ${ }^{\circledR}$ essential features are:

- it can simulate daylight for different weather patterns;

- it can take into account the geographical location of the model to simulate the season's weather patterns as well as the analyzed location's position in respect to the sun;

- it has the unique capability of incorporating interior and exterior objects taking into account their reflection coefficients and interference in the spread of light;

- it provides a variety of useful lighting design quantities, like luminance $L$, average illuminance $E_{\text {average }}$, uniformity level, that allow an adequate description of the task. 


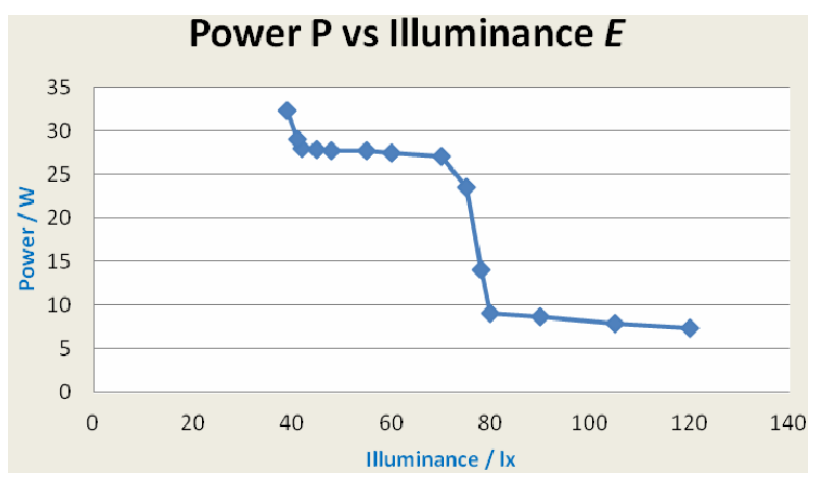

Figure 6. $P$ versus $E$ for an ELS sensor equipped ETAP luminaire.

Some key parameters set in DIALux ${ }^{\circledR}$ for the purpose of the present research are presented in Table 2.

\section{Performed Measurements and Associated Modelling}

Areas within ECE department were analyzed and specific design improvements were proposed for a chosen location (Undergraduate Lab UG4). UG4 lighting system consists of 34 luminaires, each possessing two T5 lamps with a total active power of $28 \mathrm{~W} \times 2=56 \mathrm{~W}$, and a $5 \mathrm{~W}$ ballast. The lab also has 3 windows that allow daylight to supplement lighting.

According to Standards a minimum of 320 lux must be maintained on the workplane ( $0.7 \mathrm{~m}$ height). The luminaires consume full power throughout the working day (9 am to $6 \mathrm{pm}$ ).

A superior lighting system ultimately comprising ELS sensors equipped ETAP luminaires (one lamp fixture, Figure 7) is proposed and analysed. The system complies with the illuminance level on the workplane required by Standards while providing significant energy savings.

The following steps were undertaken during the analysis process.

\subsection{DIALux ${ }^{\circledR}$ Calibration Process}

Measurements of the illuminance $E$ are performed at workplane level $0.7 \mathrm{~m}$ throughout UG4 at various distances from windows, with main lights turned off, and registered.

Using a DIALux ${ }^{\circledR}$ model for the lab based on the corresponding. DWG file (Figure 8) a simulation is undertaken (lights turned off) and the illuminance results are superimposed on the results obtained from measurements (Figure 9, where "Clear Sky" relates to outdoors conditions).

It can be seen that the DIALux ${ }^{\circledR}$ based results are different from the ones obtained by direct measurements. To address this issue changes were implemented in the DIALux $^{\circledR}$ settings as presented in Table 3.
Table 2. Key DIALux ${ }^{\circledR}$ parameters.

\begin{tabular}{cc}
\hline Parameter & Value \\
\hline Workplane height & $0.7 \mathrm{~m}$ \\
Maintenance factor & 0.77 \\
& Floor-20\% \\
Reflection coefficient & Walls—50\% \\
Wall zone & Ceiling—70\% \\
\hline
\end{tabular}

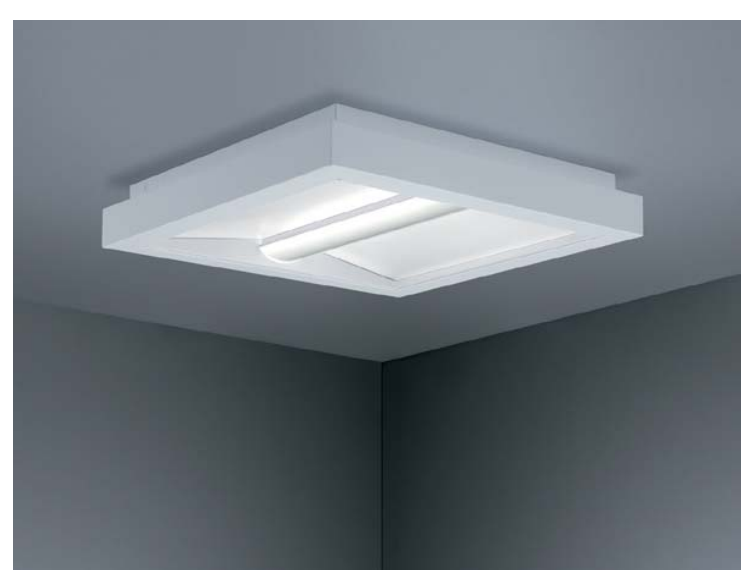

Figure 7. ETAP luminaire.

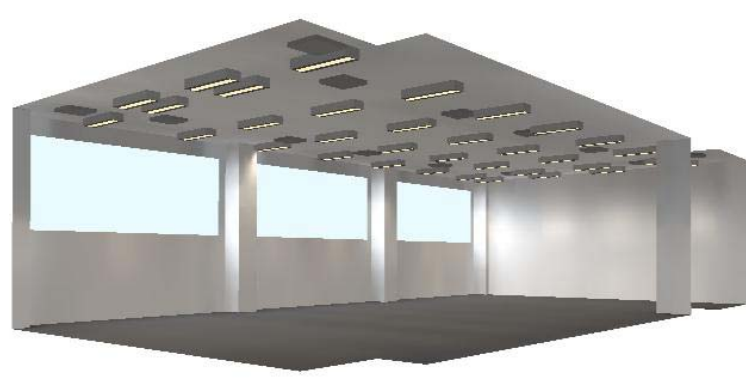

Figure 8. DIALux ${ }^{\circledR}$ model for UG4.

Following changes, simulation results became identical with direct measurements (Figure 10).

\subsection{UG4 Lab Analysis for the Existing Lighting System}

After the DIALux ${ }^{\circledR}$ calibration process for UG4 lab is concluded an analysis is undertaken for the present lighting system (power per luminaire $61 \mathrm{~W}, 34$ luminaires, 260 working days per year, 9 working hours per day) and the yearly energy consumption is calculated $\left(E_{1 \mathrm{UG} 4}=\right.$ $4853.16 \mathrm{kWh})$.

\subsection{UG4 Lab Analysis for a One Lamp Equipped, ETAP Luminaire, Lighting System}

Another analysis is performed this time for a lighting system composed of 34, one lamp equipped, ETAP lu- 


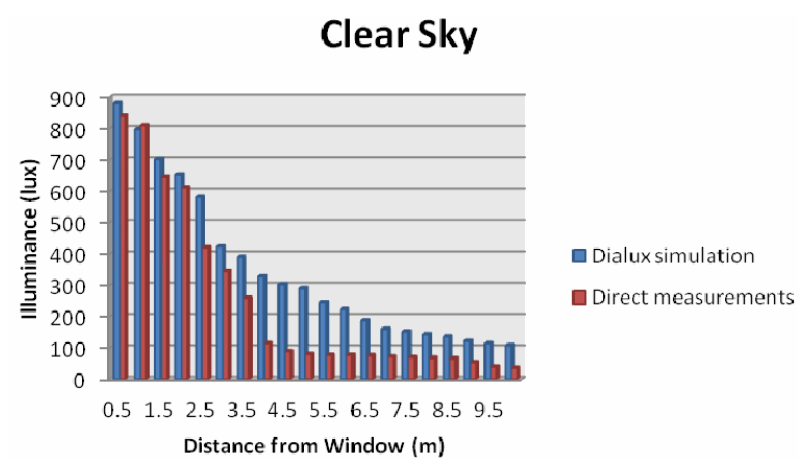

Figure 9. Real time versus DIALux ${ }^{\circledR}$ results.

Table 3. Altered DIALux ${ }^{\circledR}$ parameters.

\begin{tabular}{ccc}
\hline Parameter & Old Value & New Value \\
\hline Window transparency & $90 \%$ & $30 \%$ \\
Pollution factor & 0.8 & 0.5 \\
\hline
\end{tabular}

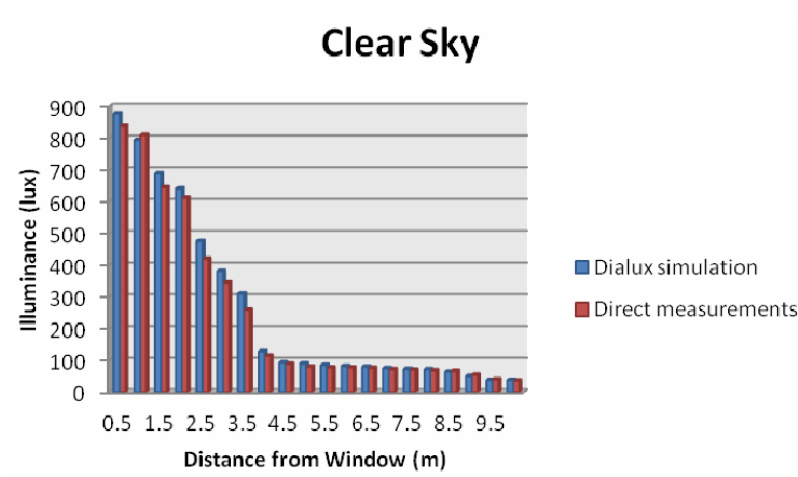

Figure 10. Real time versus DIALux ${ }^{\circledR}$ results after calibration.

minaires (power per luminaire $33 \mathrm{~W}, 34$ luminaires, 260 working days per year, 9 working hours per day). The yearly energy consumption is $E_{2 \mathrm{UG} 4}=2625.48 \mathrm{kWh}$.

\subsection{UG4 Lab Analysis for ELS Daylight Sensor, One Lamp Equipped, ETAP Luminaires, Lighting System}

Even if DIALux ${ }^{\circledR}$ cannot perform comprehensive simulations for daylight sensors-dimming ballasts equipped luminaires an interactive process is proposed that takes advantage of both DIALux ${ }^{\circledR}$ capabilities and the correlation $\mathrm{P} / \mathrm{E}$ depicted in Figure 6.

For this lighting system DIALux ${ }^{\circledR}$ settings are correlated with seasonal weather patterns, characteristic to UG4 geographical location, that were retrieved from a New Zealand national provider web site [12] and aggregated.

The interactive process consists of:

- for DIALux ${ }^{\circledR}$ corresponding weather patterns (clear sky, mixed, overcast), the $2.8 \mathrm{~m}$ height illuminance
$E_{1} \cdots E_{34}$ of each of the 34 luminaires positions in the UG4 lab (main lights turned off) is inferred from the DIALux $^{\circledR}$ graphic model (Figure 11);

- using the correlation $\mathrm{P} / E$ in Figure 6 the power $\mathrm{P}_{1} \cdots \mathrm{P}_{34}$ is determined for $E_{1} \cdots E_{34}$;

- the energy consumption is then determined accordingly, for 260 working days per year, 9 working hours per day $\left(E_{3 \mathrm{UG} 4}=1958 \mathrm{kWh}\right)$.

The results for energy consumption correlated with assigned weather patterns are displayed in Table 4.

\section{Financial Savings and Environmental Impact}

Considering the cost per kWh of energy as described in [13], that is $\$ 0.235 / \mathrm{kWh}$, the financial costs for one year are depicted in Figure 12, from where it can be inferred that the operating cost of UG4 can be reduced by $\$ 680.4$ per year. The total cost of retrofitting UG4 using the ELS sensor/ETAP luminaire (one lamp fixture) new lighting system amounts to $\$ 2380$ and can be recovered in 3.5 years.

In order to assess the reduction in the amount of $\mathrm{CO}_{2}$ the energy savings generate, from [14] it is determined that for every kWh of electricity consumed a quantity of $0.23 \mathrm{Kg}$ of $\mathrm{CO}_{2}$ is produced. The results obtained are presented in Figure 13.

It is ascertained that the proposed ELS sensor/ETAP luminaire (one lamp fixture) new lighting system contributes to an annual reduction of $665.9 \mathrm{Kg}$ in $\mathrm{CO}_{2}$ emissions.

The data used for Figures $\mathbf{1 2}$ and $\mathbf{1 3}$ are summarized in Table 5.

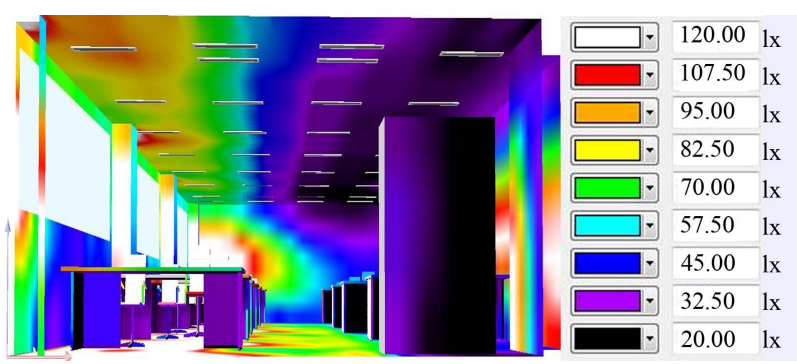

Figure 11. Determining illuminance $E$ levels in UG4.

Table 4. Energy data for the ELS sensor system.

\begin{tabular}{cccc}
\hline Weather pattern & Working days & Power [W] & Energy [kWh] \\
\hline Clear sky & 128 & 670 & 771.84 \\
Mixed sky & 54 & 820 & 398.52 \\
Overcast & 78 & 1122 & 787.64 \\
Total & 260 & 2612 & 1958 \\
\hline
\end{tabular}




\section{Financial data and savings}

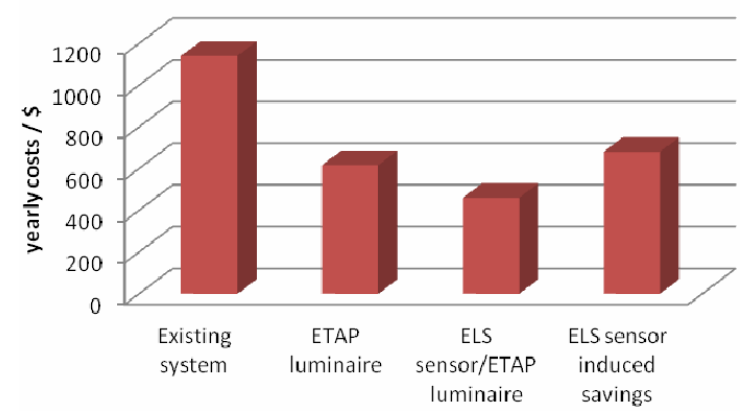

Figure 12. Annual costs and financial savings for UG4.

\section{$\mathrm{CO}_{2}$ emissions and savings}

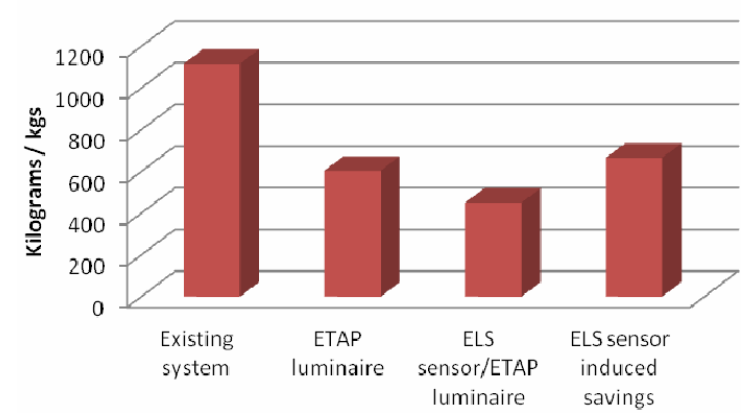

Figure 13. $\mathrm{CO}_{2}$ emissions and savings.

Table 5. Costs and $\mathrm{CO}_{2}$ emissions and savings.

\begin{tabular}{ccc}
\hline Lighting system & $\begin{array}{c}\text { Financial } \\
\text { figures [\$] }\end{array}$ & $\begin{array}{c}\mathbf{C O}_{2} \text { emission } \\
\text { figures [Kg] }\end{array}$ \\
\hline Existing system & 1140.5 & 1116.2 \\
ETAP luminaire & 617 & 603.9 \\
ELS sensor/ETAP luminaire & 460.1 & 450.3 \\
Savings & 680.4 & 665.9 \\
\hline
\end{tabular}

\section{Conclusion}

A novel technique to design smart building lighting systems or evaluate existing ones, based on a three steps approach that includes daylight harvesting (optical sensor $\mathrm{P} / E$ characteristic evaluation, room properties calibration, photometric and energy savings calculations), is proposed and tested in conjunction with a specialized lighting design software (DIALux ${ }^{\circledR}$ ) [15]. The results show an improvement in energy utilization, since important energy savings were obtained, resulting in significant financial and $\mathrm{CO}_{2}$ savings. The approach is highly advantageous for designers, investors, future tenants and environmentalists.

\section{REFERENCES}

[1] K. R. Shailesh and T. S. Raikar, "Computational Analysis of Daylight Harvesting Scheme in an Office Building in Mumbai,” IEEE International Conference on Sustainable Energy Technologies, Kandy, 6-9 December 2010.

[2] S. G. Colaco, C. P. Kurian, V. I. George and A. M. Colaco, "An Approach to Energy Harvesting for Building Automated Control System,” XXXII National Systems Conference, Roorkee, 17-19 December 2008.

[3] G. Parise and L. Martirano, "Daylight Impact on Energy Performance of Internal Lighting,” IEEE-IAS, Annual Meeting, Orlando, 9-13 October 2011.

[4] R. Leslie, R. Raghavan, O. Howlett and C. Eaton, “The Potential of Simplified Concepts for Daylight Harvesting," 2012.

http://www.Irc.rpi.edu/programs/daylighting/pdf/simplifie dConcepts.pdf

[5] California Energy Commission's Public Interest Energy Research (PIER) Program, "Daylight Harvesting Made Simple,” 2012.

http://www.energy.ca.gov/2008publications/CEC-500-20 08-067/CEC-500-2008-067-FS.PDF

[6] C. DiLouie, "Why Do Daylight Harvesting Projects Succeed or Fail?” 2012.

http://lightingcontrolsassociation.org/why-do-daylight-har vesting-projects-succeed-or-fail/

[7] A. Cziker, M. Chindris and A. Miron, "Implementation of Fuzzy Logic in Daylighting Control,” 11th International Conference on Intelligent Engineering Systems, Budapest, 29 June-2 July 2007.

[8] Standards, Australia/New Zealand Standards, 2009.

[9] Lighting ETAP, 2012. http://www.etaplighting.com/level2.aspx?seq=86\&seqpict ure $=1365$ \&name $=$ Lighting\&LangType $=1033$

[10] Tridonic Technical Data, 2012. http://www.tridonic.com/com/en/download/data_sheets/D S_PCA_T5_ECO_HE_en.pdf

[11] ETAP Lighting, “Light Controls ELS/DALI-ELS,” 2012. http://www.etaplighting.com/uploadedFiles/Downloadabl e_documentation/documentatie/ELS_en.pdf

[12] Auckland Weather Averages, 2012. http://www.climatetemp.info/new-zealand/

[13] Contact Energy, 2012. http://www.contactenergy.co.nz/web/saveenergy/applianc es

[14] $\mathrm{CO}_{2}$ Emissions, "Carbon Dioxide Generated in kg/MWh," UNEP, Senoko, 2007.

[15] DIALux ${ }^{\circledR}$. http://www.dialux.software.informer.com/ 